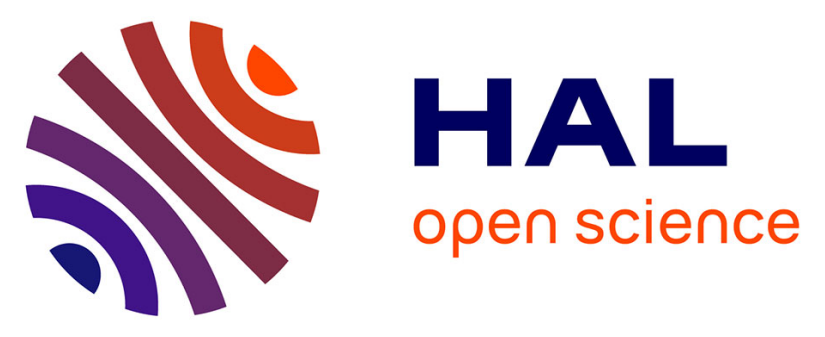

\title{
Modafinil restores memory performance and neural activity impaired by sleep deprivation in mice.
}

\author{
Christophe Piérard, Pierrette Liscia, Jean-Nicolas Philippin, Nicole Mons, \\ Thierry Lafon, Frédéric Chauveau, Pascal van Beers, Isabelle Drouet, André \\ Serra, Jean-Claude Jouanin, et al.
}

\section{To cite this version:}

Christophe Piérard, Pierrette Liscia, Jean-Nicolas Philippin, Nicole Mons, Thierry Lafon, et al.. Modafinil restores memory performance and neural activity impaired by sleep deprivation in mice.. Pharmacology Biochemistry and Behavior / Pharmacology Biochemistry and Behaviour, 2007, 88 (1), pp.55-63. 10.1016/j.pbb.2007.07.006 . hal-00275220

\section{HAL Id: hal-00275220 https://hal.science/hal-00275220}

Submitted on 22 Apr 2008

HAL is a multi-disciplinary open access archive for the deposit and dissemination of scientific research documents, whether they are published or not. The documents may come from teaching and research institutions in France or abroad, or from public or private research centers.
L'archive ouverte pluridisciplinaire HAL, est destinée au dépôt et à la diffusion de documents scientifiques de niveau recherche, publiés ou non, émanant des établissements d'enseignement et de recherche français ou étrangers, des laboratoires publics ou privés. 


\section{Modafinil restores memory performance and neural activity impaired by sleep deprivation in mice}

\section{Christophe Piérard ${ }^{1, \mathrm{CA}}$, Pierrette Liscia ${ }^{1}$, Jean-Nicolas Philippin ${ }^{2}$, Nicole Mons ${ }^{2}$, Thierry Lafon ${ }^{2}$, Frédéric Chauveau ${ }^{1,2}$, Pascal Van Beers ${ }^{1}$, Isabelle Drouet ${ }^{1}$, André Serra ${ }^{1}$, Jean-Claude Jouanin ${ }^{1}$ and Daniel Béracochéa ${ }^{2}$}

1 : Institut de Médecine Aérospatiale du Service de Santé des Armées (IMASSA)

2 : Centre de Neurosciences Intégratives et Cognitives (CNIC), UMR CNRS 5228; Universités de Bordeaux 1et2

\section{CA : corresponding author}

Christophe Piérard, Pharm.D., Ph.D.

Département de Physiologie Intégrée

Institut de Médecine Aérospatiale du Service de Santé des Armées, B.P. 73

91223 Brétigny-sur-Orge Cedex, France

Phone. 33169237756 - Fax.33169237002 - email : cpierard@imassa.fr

\section{Running head:}

Modafinil, sleep deprivation, memory and neural activity 


\section{Abstract:}

The original aims of our study have been to investigate in sleep-deprived mice, the effects of modafinil administration on spatial working memory, in parallel with the evaluation of neural activity level, as compared to non sleep-deprived animals. For this purpose, an original sleepdeprivation apparatus was developed and validated with continuous electroencephalography recording. Memory performance was evaluated using spontaneous alternation in a T-maze, whereas the neural activity level was estimated by the quantification of the c-Fos protein in various cerebral zones. This study allowed altogether:

First, to evidence that a diurnal 10-hr sleep deprivation period induced an impairment of spatial working memory.

Second, to observe a decrease in c-Fos expression after sleep deprivation followed by a behavioural test, as compared to non sleep-deprived mice. This impairment in neural activity was evidenced in areas involved in wake-sleep cycle regulation (anterior hypothalamus and supraoptic nucleus), but also in memory (frontal cortex and hippocampus) and emotions (amygdala).

Finally, to demonstrate that modafinil $64 \mathrm{mg} / \mathrm{kg}$ is able to restore on the one hand memory performance after a 10-hr sleep deprivation period, and on the other hand, the neural activity level in the very same brain areas where it was previously impaired by sleep deprivation and cognitive task.

Keywords: modafinil, sleep deprivation, memory, neural activity 


\section{Introduction:}

Modafinil (chemical name: [(diphenylmethyl) sulfinyl]-2 acetamide) has been reported as having stimulant and awakening properties without amphetamine-like side effects (Bastuji and Jouvet, 1988 ; Hermant et al., 1991 ; Lyons and French, 1991). Modafinil (Modiodal@) is successfully used in the treatment of narcolepsy and idiopathic hypersomnia without interfering, however, with nocturnal sleep (Bastuji and Jouvet, 1988). When administered to healthy subjects, modafinil provides a military interest in cases of total or partial sleep deprivation resulting from either continuous or sustained operation (Lagarde et al, 1995 ; Lagarde and Batejat, 1995 ; Caldwell et al., 2004).

Its mechanism of action could involve both norepinephrine and dopaminergic systems, through ascending pathways that are likely to promote wakefulness by activating the cortex and other forebrain targets, possibly through interaction with the hypocretin/orexin system (Boutrel and Koob, 2004 ; Willie et al., 2005). Moreover, modafinil is able to interact with norepinephrine and dopamine transporters in the brain (Madras et al., 2006), and to enhance the extracellular level of dopamine in the nucleus accumbens in rats (Murillo-Rodriguez et al., 2006), probably via the involvement of a GABAergic mechanism (Ferraro et al., 1996). Moreover, behavioural activity induced by modafinil administration could be mediated by brain alpha 1B-adrenoceptors (Stone et al., 2002). The mechanism of action of modafinil could also involve a reduction of GABA release in the cerebral cortex (Tanganelli et al., 1992 ; Piérard et al., 1997) as well as an involvement of excitatory amino acids system (Piérard et al., 1995 ; 1997) and its receptors (Lagarde et al., 1996). Modafinil could also enhance brain energy metabolism, by increasing the energetic pool of phosphocreatine in cortex, thus contributing vigilance-enhancing properties of this drug (Piérard et al., 1995). Moreover, we recently demonstrated that modafinil administered in chronically-stressed mice could interfere with glucocorticoids (Piérard et al., 2006), that are involved in the regulation 
of dopaminergic neurotransmission (Czyrak et al., 2003). However, the mechanism of action of modafinil,--as yet not fully understood--, remains largely surrounded by controversy (Saper and Scammel, 2004).

Concerning the neuroanatomical brain targets of modafinil, some authors observed that c-Fos protein expression increased in the anterior hypothalamus following modafinil administration (Lin et al., 1996 ; Engber et al., 1998) and orexin-containing neurons (Scammel et al., 2000). Neither one of these studies, however, was performed after a sleep deprivation period followed by cognitive tasks; hence the brain targets of modafinil remain a matter for debate (Gallopin et al., 2004).

From a functional viewpoint, specific neurocognitive domains including executive attention, working memory and higher cognitive functions are particularly vulnerable to sleep loss (Durmer and Dinges, 2005 ; Mu et al., 2005). More specifically, sleep loss, even moderate, compromises the function of neuronal circuits critical to subsecond attention allocation during working-memory tasks (Smith et al., 2002). The associated decrease in brain activity during working-memory tasks appears to be a function of the individual sleep-deprivation vulnerability ( $\mathrm{Mu}$ et al., 2005). Moreover, executive functioning is largely dependent on activity in the prefrontal cortex and affected negatively by one night sleep deprivation (Nilsson et al., 2005).

In addition, several studies without sleep deprivation have demonstrated that modafinil is able to improve working memory both in animals (Béracochéa et al., 2001) as well as in humans (Müller et al., 2004). There is further evidence that modafinil enhances learning processes after chronic (Béracochéa et al., 2002) or acute (Béracochéa et al., 2003) systemic administration in mice. To the best of our knowledge, very few studies investigated the effect of modafinil administration on memory and/or neural activity after sleep deprivation. In one of these studies (Pigeau et al., 1995), however, modafinil seems to restore short-term memory after prolonged sleep deprivation in humans. 
Hence, the original aims of our study have been to investigate in sleep-deprived mice, the effects of modafinil on spatial working memory with subsequent evaluation of the neural activity level in various cerebral zones, as compared to non sleep-deprived animals.

\section{Materials and Methods:}

\subsection{Animals:}

The study was conducted using male mice of the C57BL/6J strain (Iffa-Credo, Lyon, France). Upon arrival, mice were housed collectively in colony cages $(40 \mathrm{~cm}$ long x $25 \mathrm{~cm}$ high x $20 \mathrm{~cm}$ wide) matched for weight and placed in an animal room $\left(22^{\circ} \mathrm{C}\right.$ ambient temperature ; automatic light cycle 07:00 a.m. and 07:00 p.m.) with free access to food and water. Fifteen days before testing, mice were placed in individual cages and manipulated 10 minutes each day, in order to reduce interference with the experimenter. They were 5 months old on the day of the experiment.

The present study was carried out in compliance with the European Convention for the protection of Vertebrate Animals used for Experimental and other Scientific Purposes, and under the agreement \# 94001 delivered by the French Ministry of Defense, after the protocol was examined by the local ethical committee.

\subsection{Sleep deprivation model:}

\subsubsection{Apparatus:}

An original automatic total sleep-deprivation apparatus ("water box") was developed jointly by LNC and IMASSA in order to reduce stress and physical fatigue [Fig. 1]. It is constituted by a water tank of grey PVC (10 mm thickness) with rectangular section $(42 \times 32 \mathrm{~cm})$ and $22 \mathrm{~cm}$ high, containing temperature-regulated water at $31^{\circ} \mathrm{C}$. In the middle of the tank two small square platforms $(10 \times 10 \mathrm{~cm})$, without edge, are closely adjusted side by side. The surface of each 
platform is squared with deep $(3 \mathrm{~mm})$ orthogonal grooves in order to facilitate water evacuation during upward movements, and consequently to avoid that animals slip or get their feet wet. The platforms move independently with compressed-air jack. In the start position, both platforms slightly emerge from water level. Then, each platform alternatively moves below and above the surface of the water, thus forcing the mouse to a permanent motion in order to avoid water contact. The completion of one platform revolution needs 10 sec. During this period, each platform remains stable over the surface of the water for $5 \mathrm{sec}$, then goes $60 \mathrm{~mm}$ down for $2.5 \mathrm{sec}$ and immediately goes up for $2.5 \mathrm{sec}$ until the initial position. Throughout the days prior to the behavioural task, the mice were allowed to become familiar with the water box to reduce their stress level. Thus, they learn to stay at the junction of both platforms, allowing them to move from the sinking platform with a very short motion (i.e. 1 step forward then backward every 10-sec period).

\subsubsection{Validation of sleep deprivation model by EEG recording:}

The determination of the efficacy of our original sleep deprivation apparatus was performed on 14 independent mice, divided into a 10-hr diurnal sleep-deprived group $(\mathrm{n}=7)$ and a control (non sleep-deprived) group $(\mathrm{n}=7)$. All the mice were monitored by means of continuous video and EEG recording for 10 hours, between 08:00 a.m. and 08:00 p.m. Control mice were also placed in the sleep deprivation apparatus during the same period, with both platforms unmoved, thus allowing them to sleep ad libitum. Eight days before the validation experiment, animals were anaesthetized in order to place in parietal position 2 silver wire electrodes close to the dura-matter. Moreover, one reference electrode was inserted in the frontal bone. All the electrodes were fixed using acrylic dental cement (Palavit $\left.{ }^{\circledR}\right)$. The animals were then allowed to recover for 8 days. On the day of the experiment, the animals were placed in the sleep deprivation apparatus. Cortical electric activity was recorded on a Medelec ${ }^{\circledR} 1121$ EEG table. Further, spectral analysis was 
performed with the Somnologica ${ }^{\circledR}$ v.3.1.3 software. In addition to the observation of animals, the wakening status was characterized on recordings by low amplitude $(<200 \mu \mathrm{V})$ and high frequency $(>40 \mathrm{~Hz})$ waves, and the sleep status by the occurrence of waves with an amplitude higher than $200 \mu \mathrm{V}$, and of $\delta(0.5-4.5 \mathrm{~Hz})$ or $\theta(4.5-9.5 \mathrm{~Hz})$ frequencies. Signal analysis was performed continuously throughout the $10 \mathrm{hrs}$ of sleep deprivation, for $5 \mathrm{~s}$ periods. Moreover, selective spectral analysis was performed for power in the $(8-9 \mathrm{~Hz}) \theta$ band frequencies, considered as an index of alertness or attention during wakefulness in the rodents (Willie et al., 2005).

\subsection{Memory testing:}

The behavioural task used to test working memory [Fig. 2] is based on spontaneous alternation behavior (SA), which does not require the use of food reinforcement to emerge. SA is the innate tendency of rodents whereby over a series of trials run in a T-maze, they alternate at each successive trial the choice of the goal arm ((except for the first trial). Repetitive testing constitutes a potent source of proactive interference. From trial to trial, accurate performance at a given trial (N) requires for subjects to be able to discriminate the specific target trial $\mathrm{N}-1$ from the interfering trial $\mathrm{N}-2$. The target information required for successful performance varies from trial to trial, so that the subject is not only required to keep temporarily in short-term memory specific information, but also to reset it over successive runs. The resetting mechanisms and cognitive flexibility required to alternate over successive runs are major components of working memory processes. Working memory is a component of the sequential alternation task, since SA rates are dependent on the length of the intertrial delay interval, and/or the place of the trial in the series. Indeed, repetitive testing constitutes a potent source of proactive interference. Thus, the sequential alternation procedure is relevant to assess delay-dependent working memory in mice (Béracochéa and Jaffard, 1990 ; Béracochéa et al., 1995). 
The tests were carried out in a T-maze constructed of opaque grey PVC. Stem and arms were $35 \mathrm{~cm}$ long, $10 \mathrm{~cm}$ wide, and $25 \mathrm{~cm}$ high. The start box $(10 \times 12 \mathrm{~cm})$ was separated from the stem by a vertical sliding door. Vertical sliding doors were also placed at the entrance of each arm. A low-intensity diffuse illumination (10 lux) was provided above the apparatus. Between two trials, the apparatus was cleaned using $70 \%$ alcohol and water, in order to remove any olfactive cue. An alternation response was considered each time the subject entered the arm opposite to the one visited on the immediately previous trial. Alternation rate was expressed in percentage relative to the maximal alternation rate of $100 \%$ (obtained when the subject never returned into the same arm over two consecutive trials).

For all the animals, the following procedure was used:

On D-4 (four days before the day of the test), all the animals were allowed to freely explore the apparatus $10 \mathrm{~min}$ in the morning and $10 \mathrm{~min}$ in the afternoon, in order for them to become familiar with the experimental conditions. Between both sessions, animals were replaced in their individual cage in the animal room.

From D-3 to D-1, the animals had to complete two daily training sessions of SA (6 sessions in total), in order to foster the development of the alternation behavioural pattern and to familiarize them with the opening and/or closing of the doors over successive runs. Each session included 6 trials, separated by a 30-s intertrial delay.

On D0 (the day of the experiment), behavioural testing was performed $30 \mathrm{~min}$ after the end of the sleep deprivation period and modafinil (or vehicle) injection. This delay is required for the development of the pharmacological action of modafinil. The animals were not allowed to sleep during this 30 -min delay, because recovery sleep might interfere with Fos staining (Cirelli, 2002). As stated here above, all the subjects were exposed to 6 successive trials (intertrial delay: $30 \mathrm{~s})$. 


\subsection{Behavioural study:}

Previous experiments have shown that a sleep deprivation period of 24 hrs totally disrupted the ability of mice to run the alternation task, the mice choosing to sleep rather than to explore the maze. In contrast, a 3-hr sleep deprivation period had no effect on memory performance as regards non sleep-deprived animals (unpublished data). According to these previous experiments, we decided to study the effects on memory of an intermediate 10-hr sleep deprivation period and modafinil. Thirty-eight mice randomized between the 5 following groups were used: i) NSD (non sleep-deprived ; $\mathrm{n}=8)$; ii) SD (10-hr sleep-deprived ; $\mathrm{n}=8)$; iii) SD + vehicle (10-hr sleepdeprived + vehicle $; \mathrm{n}=6) ;$ iv) SD + M32 (10-hr sleep-deprived + modafinil $32 \mathrm{mg} / \mathrm{kg} ; \mathrm{n}=8) ; \mathrm{v})$ SD + M64 (10-hr sleep-deprived + modafinil $64 \mathrm{mg} / \mathrm{kg} ; \mathrm{n}=8)$. The sleep deprivation period took place from 08:00 a.m until 08:00 p.m.

Modafinil administration: modafinil, insoluble in water, was suspended in an $0.5 \%$ solution of gum tragacanth (vehicle). Modafinil suspension or vehicle alone were injected i.p. after the sleep deprivation period, 30 minutes before the behavioural test session began. According to our previous study (Béracochéa 2001 ; Piérard 2006), the administered doses of modafinil were of 32 and 64 $\mathrm{mg} / \mathrm{kg}$ for the M32 and M64 groups respectively (injected volume: $0.1 \mathrm{ml} / 10 \mathrm{~g}$ mouse).

Statistical analysis: in our behavioural procedure, only mice having alternated at the second trial were selected for further statistical analysis of behavioural data (Piérard et al., 2006). This behavioural criterion ensured that motor abilities and motivation to alternate are equivalent between subjects and not impaired by sleep deprivation and/or modafinil. Thus, all the groups exhibit alternation rates of $100 \%$ at the second trial [Fig. 5]. Using this procedure, only one mouse of the [SD] group and one mouse of the [SD + M32] group were not taken into account for analysis. Moreover, mice of the [SD] and [SD + vehicle] groups were gathered together for statistical analysis. Statistical analysis was performed using Statview ${ }^{\circledR}$ v.5.0 software. ANOVA was performed to evidence the effects of a 10-hr sleep deprivation period (followed or not by modafinil 
administration) on alternation rates. Further comparisons between individual groups were performed with the Scheffe post-hoc test. Significance was accepted at p values below 0.05.

\subsection{Immunohistochemical study (c-Fos analysis):}

The quantification of c-Fos protein expression in the brain is currently used as a marker of functional activity (see Krukoff 1999 for review). C-Fos analysis was performed on the 10-hr sleep-deprived groups, as compared to the control non sleep-deprived group [NSD]. Immediately after the alternation task, 12 mice of [NSD], [SD], and [SD + M64] groups (4 randomized mice for each group) were anaesthetized (ketamine $100 \mathrm{mg} / \mathrm{kg}$ + xylazine $10 \mathrm{mg} / \mathrm{kg}$; injected volume: 0.1 $\mathrm{ml} / 10 \mathrm{~g}$ mouse). They were then perfused in the left ventricule with $100 \mathrm{ml} \mathrm{NaCl} 0.9 \%$ followed by $100 \mathrm{ml}$ paraformaldehyde $4 \%$ to fix tissue before the brain was removed. Fixed brains were cut in frontal sections of $50 \mu \mathrm{m}$ each, using a freezing microtome. Sections were incubated with a primary antibody specific of Fos protein (Calbiochem $\left.{ }^{\circledR}\right)$, then with a biotinyled secondary antibody (specific of the primary antibody), and finally with the avidine-biotine-peroxydase complex Vectastain $\left.{ }^{\circledR}\right)$. C-Fos immunoreactivity was revealed using diaminobenzidine. Different brain structures were analysed with the image analysis system Biocom 2000 (visiol@b 2000 software) coupled with a microscope. The analysis concerned the brain structures involved i) in the regulation of the wake-sleep cycle : anterior hypothalamus and supraoptic nucleus, ii) in memory : frontal cortex and hippocampus areas (CA1 and dentate gyrus) and iii) in emotions : amygdala.

The quantification of Fos-positive nuclei in the studied brain regions following the alternation task was expressed in mean counts $/ \mathrm{mm}^{2}$. Moreover, for a given area, the results were expressed in relative variations as compared to $[\mathrm{NSD}]$ mice. Intra-zone comparisons to [NSD] mice were performed by the Student $t$ test. Significance was accepted at $\mathrm{p}$ values below 0.05 . 


\section{Results:}

\subsection{EEG validation of the sleep deprivation model:}

The behavioural observation of video recordings obtained during the 10-hr sleep deprivation period shows that mice remained awake $100 \%$ of the time in the water-box. The [Fig. 3] represents an EEG sample obtained during the occurrence of a short sleep event. The [Fig. 4], obtained from EEG data, gives the repartition (in terms of numbers and mean durations of sleep events) during the 10-hr diurnal sleep deprivation period. The mean cumulated duration of sleep episodes during the 10-hr sleep deprivation period was of about $0.66 \pm 0.23 \min (\mathrm{m} \pm \mathrm{SEM} ; \mathrm{n}=7)$, i.e. $0.11 \pm 0.04 \%$, whereas it was of $314.13 \pm 27.56 \min (\mathrm{m} \pm \mathrm{SEM} ; \mathrm{n}=7)$, i.e. $52.36 \pm 4.59 \%$ in control animals. Thus, the efficacy of our sleep-deprivation apparatus is of $99.79 \%$. The greatest number and duration of sleep episodes occurred during the first hour spent on the apparatus (between 08:00 and 09:00 a.m.), i.e. at the beginning of the diurnal rest phase for rodents. On the other hand, spectral analysis of the $\theta$ band frequencies $(8-9 \mathrm{~Hz})$ during wakefulness shows that attention is continuously impaired from the first hour of the sleep deprivation (08:00-09:00 a.m.) until the fourth hour (11:00-12:00 a.m.). Minimal attention also occurred for the seventh hour (02:00-03:00 p.m.). Then attention increased until the end of the sleep deprivation period (i.e. 05:00-06:00 p.m.).

\subsection{Effects of sleep deprivation:}

\subsubsection{On spatial working memory: [Fig. 5]}

A two-way ANOVA on the overall 4 groups $[\mathrm{NSD}](\mathrm{n}=8) ;[\mathrm{SD}](\mathrm{n}=13) ;[\mathrm{SD}+\mathrm{M} 32](\mathrm{n}=$ 7) and [SD + M64] $(n=8)$ evidences a significant interaction between groups and interfering trials (trials \# 3-6) $[\mathrm{F}(3,32)=4.47 ; \mathrm{p}<0.009]$. 
Furthermore, individual comparisons show that the alternation rate of the [SD] group is significantly decreased $(\mathrm{p}<0.001)$ as compared to the $[\mathrm{NSD}]$ group, thus evidencing the impairment spatial working memory induced by a 10-hr total sleep deprivation period.

\subsubsection{On neural activity: [Table I]}

For a given area, ANOVA performed on groups (SD, NSD, SD+M64) showed a global significant inter-groups difference as mentioned in Table $1(\mathrm{p}<0.05$ in all comparisons). The mice of the [SD] group show a significantly decreased c-Fos staining in the anterior hypothalamus and supraoptic nucleus (- 23 and $-18 \%$ respectively; $\mathrm{p}<0.05$ ), as compared to [NSD] mice. Moreover, the decrease in c-Fos staining is also evidenced in CA1 and dentate gyrus of hippocampus $(-18 \% ; \mathrm{p}<0.05)$, frontal cortex $(-15 \% ; \mathrm{p}<0.03)$ and amygdala $(-13 \% ; \mathrm{p}<$ 0.05), as compared to [NSD] mice.

\subsection{Effects of modafinil after a 10-hr sleep deprivation period:}

\subsubsection{On spatial working memory: [Fig. 5]}

Individual comparisons show that the alternation rate of the [SD + M32] group is not significantly different from [SD] group. On the contrary, the alternation rate of the [SD + M64] group is significantly increased as compared to the [SD] group $(\mathrm{p}<0.001)$, but not significantly different from the [NSD] group. Thus, modafinil ( $64 \mathrm{mg} / \mathrm{kg}$, but not $32 \mathrm{mg} / \mathrm{kg}$ ) is able to restore the spatial working memory performance that was previously impaired by a 10-hr sleep-deprivation period.

\subsubsection{On neural activity: [Table I]}

For all the studied brain regions, statistical analysis shows that c-Fos staining for the [SD + M64] group is not different as compared to [NSD] group. Thus, modafinil $(64 \mathrm{mg} / \mathrm{kg})$ is able to 
restore neural activity in the very same cerebral structures where it was previously decreased by a 10-hr sleep deprivation period.

\section{Discussion:}

The current study evidenced that a total 10 -hr diurnal sleep deprivation is able to impair working memory performance in mice. Moreover, the $10-\mathrm{hr}$ sleep deprivation period is able to impair neural activity in the cerebral areas involved in sleep/wake cycle regulation, memory and emotions. Both these impairments could be completely reversed by modafinil administration at the dose of $64 \mathrm{mg} / \mathrm{kg}$ i.p. (but not of $32 \mathrm{mg} / \mathrm{kg}$ ).

Thus, the present study shows for the first time that modafinil is able to restore both memory performance and neural activity previously impaired by a prolonged sleep deprivation. Besides pharmacological means (for example IMAO that completely suppresses paradoxical sleep), or gentle handling (Palchykova et al., 2006), several sleep deprivation apparatuses (mainly for rats or bigger animals) are described in the literature (Vogel et al., 1975 ; Rechtschaffen et al., 1989). Furthermore, some of them allow selective REM or non REM sleep deprivation, with the help of polygraphic recordings. In the present study, we used an original total sleep deprivation model. We can assume that stress in our sleep deprivation model is not a cause for the memory impairments observed in SD subjects. Indeed, the advantage of our alternative platforms apparatus (water box) is to induce very low stress level. Thus, at any moment the animal has an emerging security platform readily available, allowing it to stay out of water. Furthermore, physical fatigue is minimal because the animal learns to stay at the junction of both platforms, thus allowing it to leave the downward platform very quickly, with a very short motion. In addition, the stress effect is observable only during the first hour of the SD period, and we found that mice submitted to a 3 hours SD period did not evidenced memory impairments (unpublished data). This means that the stress component 
involved in the first hour is not important enough to induce a memory deficit. Continuous EEG analysis (performed on independent mice during the validation phase) allowed to determine the efficacy score $(99.79 \%)$ of our sleep deprivation apparatus. On the other hand, EEG recording allowed to evidence variations of attention by the means of the spectral analysis of the $\theta$ band frequencies $(8-9 \mathrm{~Hz})$ during wakefulness.

In humans, modafinil administered in non sleep-deprived subjects at a therapeutic dose (100 or $200 \mathrm{mg}$ ) has no effect on spatial working memory, nor on long-term memory. Thus, modafinil could not be considered as a cognitive enhancer in non sleep-deprived healthy subjects (Randall et al., 2005). On the opposite, previous results of our laboratory obtained on healthy sleepdeprived adults (after a 60-hr sleep deprivation period) showed that modafinil is able to restore the overall psychomotor performance to the non sleep-deprived levels (Lagarde and Batejat, 1995). This result was confirmed by a recent work (Wesensten, 2006). Thus, we logically decided in the present study to use the non sleep-deprived animals as controls for post-hoc statistical analysis. The latter result is consistent with the present study, in which the powerful wakening effect of modafinil is clearly evidenced on working memory performance after $10 \mathrm{hrs}$ sleep deprivation. Indeed, after modafinil administration, these animals retrieved their exploratory behavior and a normal working memory performance.

Fos is the protein product of the immediate early gene c-fos. In response to a stimulus, one observes first an increase in c-fos mRNA levels, which is soon followed by the synthesis of Fos protein. Fos protein is a transcription factor that, by binding to DNA regulatory regions, can control the expression of many "target" genes. In the CNS, c-fos can be induced by many different stimuli, and it is probably a simpler task to list those stimuli that do not induce c-fos. However, the expression of Fos protein is classically considered as a relevant indicator of neural activity. In sleep-deprived rats, c-fos expression in several brain areas is higher with respect to control animals (Cirelli et al., 1995). Indeed, after a few hours of spontaneous waking or sleep deprivation, c-fos 
and other IEGs is high in cerebral cortex, hypothalamus, septum, and several thalamic and brainstem nuclei (Cirelli and Tononi, 2000). In addition, Terao et al. (2003) evidenced a statistically significant increase in c-fos mRNA in mouse cerebral cortex, basal forebrain, thalamus and cerebellum following a 6-hr sleep deprivation. Contrariwise the expression of c-fos in mouse brain is very low after a few hours of sleep/inactivity (Basheer et al., 1997). Considered together, these results indicate that c-fos expression is associated with waking, but is not proportional to the amount of previous waking (Cirelli and Tononi, 2000). Interestingly, however, it is noteworthy that none of the above studies submitted animals to a behavioural task before Fos analysis. However, Stone et al (2006) reported that brain areas involved in positively motivated behavior exhibited a decrease in Fos activity, in contrast to brain areas mediating stress effects (e.g. Paraventricular nucleus) which exhibited an increase in Fos activity. In the present study, we evidenced significant decreases in c-fos staining after a 10-hr sleep deprivation in all the studied brain areas, as compared to non SD mice. Thus, since our SD model did not induced stress, our results corroborate the general conclusions drawn by Stone et al (2006) concerning the areas which are not involved in stress effects, thus strengthening our hypothesis that stress is not involved in the SD-induced memory impairments. Thus, we can hypothesise that the combination between sleep deprivation on the one hand with the behavioural task (spontaneous alternation) on the other hand might be responsible for these observed decreases in Fos staining. Indeed, this hypothesis is sustained by the work of Célérier (2004), who already found that the combination of a moderate stress with a cognitive task reduced c-fos expression in the hypothalamus, whereas stress only increased Fos staining in this area, as compared with non-stressed animals. Concerning the effects of modafinil on Fos labelling in brain, modafinil induced marked Fos staining in anterior hypothalamus on cat (Lin et al. ; 1996). Moreover, Engber et al. (1998) found by c-Fos immunohistochemistry that the neural targets for modafinil not only include anterior hypothalamus, but also amygdala. These results are consistent with our present work, where Fos staining was 
previously decreased in anterior hypothalamus and amygdala after sleep deprivation and cognitive task, and then restored by modafinil. However, Scammel et al. (2000) did not evidence a significant increase in Fos expression in the anterior hypothalamic area after modafinil administration in rat.

Moreover, the debate remains open about a possible relationship between neural activity on the one hand, and memory performance on the other hand. A spatial relationship seems at least to exist, because neural activity variations (evidenced by Fos staining after sleep deprivation followed or not by modafinil administration), partly occurred in the two main brain areas that are involved in memory (i.e. frontal cortex and hippocampus). However, the temporal relationship between memory performance and neural activity changes is not clearly established. In addition, further studies are also needed in order to determine the mechanism of action of modafinil on the recovery of both memory performance and neural activity after sleep deprivation. One could also wonder if a single mechanism of action could explain both the wakening and memory-enhancing effects of modafinil.

A specific contribution of the present study is the evidence, in sleep-deprived mice, of a modafinil-induced enhancement of Fos labelling in amygdala, the main brain area involved in emotions. Indeed, such a finding corroborates our previous study (Piérard et al., 2006) in which we observed an interaction between modafinil, stress and memory. Moreover, as for many memory enhancing drugs, such as beta-CCM (Célérier et al., 2004), an anxiety-like action of modafinil was previously found (unpublished data). In addition, anxiogenic treatments such as cholecystokinin (CCK) fragments increase Fos labelling in several brain regions including amygdala and hypothalamus (Netto and Guimarães, 2004). Thus, the anxiety-like action of modafinil might contribute to its neural activity-recovering effect.

Finally, it will be relevant to extend the present immunohistochemical experiment by the dynamic study, not only of neural activation (using Fos staining), but also as regards neuronal 
plasticity (by the means of the quantification of MAP2 and synaptophysin protein expression) after sleep deprivation and/or modafinil administration, in the same brain areas as above.

\section{Conclusion:}

The current study used a new and original low-stress total sleep deprivation device, that allowed to evidence that a diurnal 10-hr sleep deprivation period induced an impairment of spatial working memory. We observed in the same animals a decrease in Fos protein expression (maybe due to the combination between sleep deprivation and behavioural test), in areas involved in wakesleep cycle regulation (anterior hypothalamus and supraoptic nucleus), but also in memory (frontal cortex and hippocampus) and emotions (amygdala). In a second step, we observed the ability of modafinil (64 but not $32 \mathrm{mg} / \mathrm{kg}$ ) to restore, after 10 hrs sleep deprivation, both the previously impaired working-memory performance and neural activity.

\section{Acknowledgments:}

The authors are grateful to Frances Ash (ashberac@free.fr) for language assistance.

This research was supported by a grant (Opération n00 CO 022 - PEA 9808 12) from Délégation Générale pour l'Armement (DGA/DET/SCET/CEP/SHP, Paris, France) and by the CNRS. 


\section{References:}

Basheer R, Sherin JE, Saper CB, Morgan JI, McCarley RW, Shiromani PJ. Effects of sleep on wake-induced c-fos expression. J Neurosci $1997 ; 17$ : 9746-50.

Bastuji H, Jouvet M. Successful treatment of idiopathic hypersomnia and narcolepsy with modafinil. Prog Neuropsychopharmacol Biol Psychiatry $1988 ; 12 ; 695-700$.

Béracochéa D, Jaffard R. Effects of ibotenic acid lesions of the mammillary bodies on spontaneous and rewarded spatial alternation in mice. J Cogn Neurosci $1990 ; 2 ; 133-40$.

Béracochéa D, Krazem A, Jaffard R. Methyl beta-carboline-3-carboxylate reverses the working memory deficits induced either by chronic alcohol consumption or mammillary bodies lesions in mice. Psychobiology $1995 ; 23 ; 52-8$.

Béracochéa D, Cagnard B, Célérier A, Le Merrer J, Pérès M, Piérard C. First evidence of a delay-dependant working memory-enhancing effect of modafinil in mice. Neuroreport $2001 ; 12$; $375-8$.

Béracochéa D, Célérier A, Borde N, Valleau M, Pérès M, Piérard C. Improvement of learning processes following chronic systemic administration of modafinil in mice. Pharmacol Biochem Behav $2002 ; 73: 723-8$.

Béracochéa D, Célérier A, Pérès M, Piérard C. Enhancement of learning processes following an acute modafinil injection in mice. Pharmacol Biochem Behav 2003 ; 76 ; 473-9.

Boutrel B, Koob GF. What keeps us awake : the neuropharmacology of stimulants and wakefulness-promoting medications. Sleep $2004 ; 27$; 1181-94.

Caldwell JA, Caldwell JL, Smith JK, Brown DL. Modafinil's effects on simulator performance and mood in pilots during 37 hours without sleep. Aviat Space Environ Med 2004 ; 75 ; 777-84.

Célérier A. Etude des effets du stress sur les processus de restitution mnésique chez la souris normale ou alccolisée : approches comportementale, pharmacologique et neurobiologique. Thèse Université Bordeaux 1, 27 juin 2002, $\mathrm{n}^{\circ}$ d'ordre 2521.

Célérier A, Piérard C, Béracochéa D. $\beta$-CCM enhances retrieval of serial contextual but not of serial spatial memory in mice. Behav Pharmacol $2004 ; 15 ; 123-31$.

Cirelli C, Pompeiano M, Tononi G. Sleep deprivation and c-fos expression in the rat brain. J Sleep Res $1995 ; 4$; 92-106.

Cirelli C, Tononi G. On the functional significance of c-fos induction during the sleep-waking cycle. Sleep $2000 ; 23 ; 453-69$. 
Cirelli C. How sleep deprivation affects gene expression in the brain : a review of recent findings. J Appl Physiol 2002 ; 92 ; 394-400.

Czyrak A, Mackowiak M, Chocyk A, Fijal K, Wedzony K. Role of glucocorticoids in the regulation of dopaminergic neurotransmission. Pol J Pharmacol 2003 ; 55 ; 667-74.

Durmer JS, Dinges DF. Neurocognitive consequences of sleep deprivation. Semin Neurol $2005 ; 25 ; 117-29$.

Engber TM, Koury EJ, Dennis SA, Miller MS, Contreras PC, Bhat RV. Differential patterns of regional c-Fos induction in the rat brain by amphetamine and the novel wakefulness-promoting agent modafinil. Neurosci Lett $1998 ; 241 ; 95-8$.

Ferraro L, Tanganelli S, O-Connor WT, Antonelli T, Rambert F, Fuxe K. The vigilance promoting drug modafinil increases dopamine release in the rat nucleus accumbens via the involvement of a local GABAergic mechanism. Eur J Pharmacol 1996 ; 306 ; 33-9.

Gallopin T, Luppi PH, Rambert FA, Frydman A, Fort P. Effect of the wake-promoting agent modafinil on sleep-promoting neurons from the ventrolateral preoptic nucleus : an in vivo pharmacologic study. Sleep $2004 ; 27 ; 19-25$.

Hermant JF, Rambert F, Duteil J. Awakening properties of modafinil : effect of nocturnal activity in monkeys (Macaca mulatta) after acute and repeated administration. Psychopharmacology $1991 ; 103 ; 28-32$.

Krukoff TL. C-fos expression as a marker of functional activity in the brain. In : Boulton AA, Baker GB, Bateson AN, editors. Neuromethods, vol. 33 : Cell Neurobiology Techniques. Totowa (New Jersey) : Humana Press, 1999, pp 213-30.

Lagarde D, Batejat D. Disrupted sleep-wake rhythm and parformance : advantages of modafinil. Milit Psychol $1995 ; 7$; 165-91.

Lagarde D, Batejat D, Van Beers P, Sarafian D, Pradella S. Interest of modafinil, a new psychostimulant, during a sixty-hour sleep deprivation experiment. Fundam Clin Pharmacol 1995 ; $9 ; 271-9$.

Lagarde D, Girault S, Le Ray D, Piérard C. Modulation of the stimulating effect of modafinil by glutamate agonists and antagonists. Med Sci Res 1996 ; 24 ; 687-90.

Lin JS, Hou Y, Jouvet M. Potential brain neuronal targets for amphetamine, methylphenidate, and modafinil-induced wakefulness, evidenced by c-fos immunocytochemistry in the cat. Proc Natl Acad Sci USA 1996 ; 93 ; 14128-33.

Lyons TJ, French J. Modafinil : the unique properties of a new stimulant. Aviat Space Environ Med $1991 ; 62$; 432-5. 
Madras BK, Xie Z, Jassen A, Panas H, Lynch L, Johnson R, et al. Modafinil occupies dopamine and norepinephrine transporters in vivo and modulates the transporters and trace amine activity in vitro. J Pharmacol Exp Ther 2006 ; 319 ; 561-9.

Mu Q, Mishory A, Johnson KA, Nahas Z, Kozel FA, Yamanaka K, et al. Decreased brain activity during a working memory task at rested baseline is associated with vulnerability to sleep deprivation. Sleep $2005 ; 28 ; 433-46$.

Müller U, Steffenhagen M, Regenthal R, Bublak P. Effects of modafinil on working memory processes in humans. Psychopharmacology $2004 ; 177 ; 161-9$.

Murillo-Rodriguez E, Haro R, Palomero-Rivero M, Millan-Aldaco D, Drucker-Colin R. Modafinil enhances extracellular levels of dopamine in the nucleus accumbens and increases wakefulness in rats. Behav Brain Res 2006 ; in press.

Netto CF, Guimarães FS. Anxiogenic effect of cholecystokinin in the dorsal periaqueductal gray. Neuropsychopharmacology 2004 ; 29 ; 101-7.

Nilsson JP, Soderstrom M, Karlsson AU, Lekander M, Akerstedt T, Lindroth NE, et al. Less effective executive functioning after one night's sleep deprivation. J Sleep Res 2005 ; 14 ; 1-6.

Palchykova S, Winsky-Sommerer R, Meerlo P, Dürr R, Tobler I. Sleep deprivation impairs object recognition in mice. Neurobiology of learning and memory $2006 ; 85 ; 263-71$.

Piérard C, Satabin P, Lagarde D, Barrère B, Guézennec CY, Menu JP, et al. Effects of a vigilance-enhancing drug, modafinil, on rat brain metabolism : a $2 \mathrm{D}{ }^{1} \mathrm{H}-\mathrm{NMR}$ study. Brain Res $1995 ; 693 ; 251-6$.

Piérard C, Lagarde D, Barrère B, Duret P, Cordeiro C, Guézennec CY, et al. Effects of a vigilance-enhancing drug, modafinil, on rat brain cortex amino acids : a microdialysis study. Med Sci Res 1997 ; 25 ; 51-4.

Piérard C, Liscia P, Valleau M, Drouet I, Chauveau F, Huart B., et al. Modafinil-induced modulation of working memory and plasma corticosterone in chronically-stressed mice. Pharmacol Biochem Behav 2006 ; 83 ; 1-8.

Pigeau R, Naitoh P, Buguet A, McCann C, Baranski J, Taylor M, et al. Modafinil, damphetamine and placebo during 64 hours of sustained mental work. I. Effects on mood, fatigue, cognitive performance and body temperature. J Sleep Res 1995 ; 4 ; 212-28.

Randall DC, Viswanath A, Bharania P, Elsabagh SM, Hartley DE, Shneerson JM, et al. Does modafinil enhance cognitive performance in young volunteers who are not sleep-deprived ? J Clin Psychopharmacol $2005 ; 25 ; 175-9$.

Rechtschaffen A, Bergmann BM, Everson CA, Kushida CA, Gilliland MA. Sleep deprivation in the rat: X. Integration and discussion of the findings. Sleep $1989 ; 12 ; 68-87$. 
Saper CB, Scammel TE. Modafinil : a drug in search of a mechanism. Sleep $2004 ; 27$; 19-25.

Scammel TE, Estabrooke IV, McCarthy MT, Chemelli RM, Yanagisawa M, Miller MS, et al. Hypothalamic arousal regions are activated during modafinil-induced wakefulness. J Neurosci $2000 ; 20 ; 8620-8$.

Smith ME, McEvoy LK, Gevins A. The impact of moderate sleep loss on neurophysiologic signals during working-memory task performance. Sleep $2002 ; 25$ : 784-94.

Stone EA, Cotecchia S, Lin Y, Quartermain D. Role of brain alpha 1B-adrenoceptors in modafinil-induced behavioural activity. Synapse $2002 ; 46: 269-70$

Stone EA, Lehmann ML, Lin Y, Quartermain D. Depressive behavior in mice due to immune stimulation is accompagned by reduced neural activity in brain regions involved in positively motivated behavior . Biol. Psychiatry 2006; 60: 803-11.

Tanganelli S, Fuxe K, Ferraro L, Janson AM, Bianchi C. Inhibitory effects of the psychoactive drug modafinil on gamma-aminobutyric acid outflow from the cerebral cortex of the awake freely moving guinea-pig. Possible involvement of 5-hydroxytryptamine mechanisms. Naunyn Schmiedebergs Arch Pharmacol 1992 ; 345 ; 461-5.

Terao A, Greco MA, Davis RW, Heller HC, Kilduff TS. Region-specific changes in immediate early gene expression in response to sleep deprivation and recovery sleep in the mouse brain. Neuroscience $2003 ; 120 ; 1115-24$.

Vogel GW. A review of REM sleep deprivation. Arch Gen Psychiatry $1975 ; 32 ; 749-53$.

Wesensten NJ. Effects of modafinil on cognitive performance and alertness during sleep deprivation. Curr Pharm Des 2006 ; 12 ; 2457-71.

Willie JT, Renthal W, Chemelli RM, Miller MS, Scammel TE, Yanagisawa M, Sinton CM. Modafinil more effectively induces wakefulness in orexin-null mice than in wild-type littermates. Neuroscience $2005 ; 130 ; 983-95$. 


\section{Figure captions:}

\section{Figure 1:}

Total sleep deprivation apparatus "water box".

\section{Figure 2:}

Behavioural task (spontaneous alternation in a T-maze) used to assess delay-dependent working memory in mice.

\section{Figure 3:}

EEG sample obtained during the occurrence of a short sleep event (14 sec).

\section{Figure 4:}

Mean repartition of sleep events during a diurnal 10-hr sleep deprivation period ( $\mathrm{n}=7$ mice).

Left scale: mean number (bars) - Right scale: mean duration (lines) in min.

\section{Figure 5:}

Effects of a 10-hr sleep deprivation period and modafinil on spatial working memory performance. Results are expressed as means \pm SEM. NSD: non sleep-deprived ; SD: 10-hr sleep-deprived ; SD + M32: 10-hr sleep-deprived + modafinil $32 \mathrm{mg} / \mathrm{kg}$; SD + M64: 10-hr sleep-deprived + modafinil $64 \mathrm{mg} / \mathrm{kg}$. ; ***: $\mathrm{p}<0.001$.

\section{Table I:}

Quantification of Fos-positive nuclei immediately after the alternation task. Results are expressed as mean counts $/ \mathrm{mm}^{2} \pm$ SEM. NSD: non sleep-deprived ; SD: 10-hr sleep-deprived ; SD + M64: 10-hr sleep-deprived + modafinil $64 \mathrm{mg} / \mathrm{kg}$. For each brain structure, F value and significance of ANOVA is given (italic characters). Intra-zone comparisons to NSD animals : ${ }^{*}: \mathrm{p}<0.05$; n.s. : non significant. 


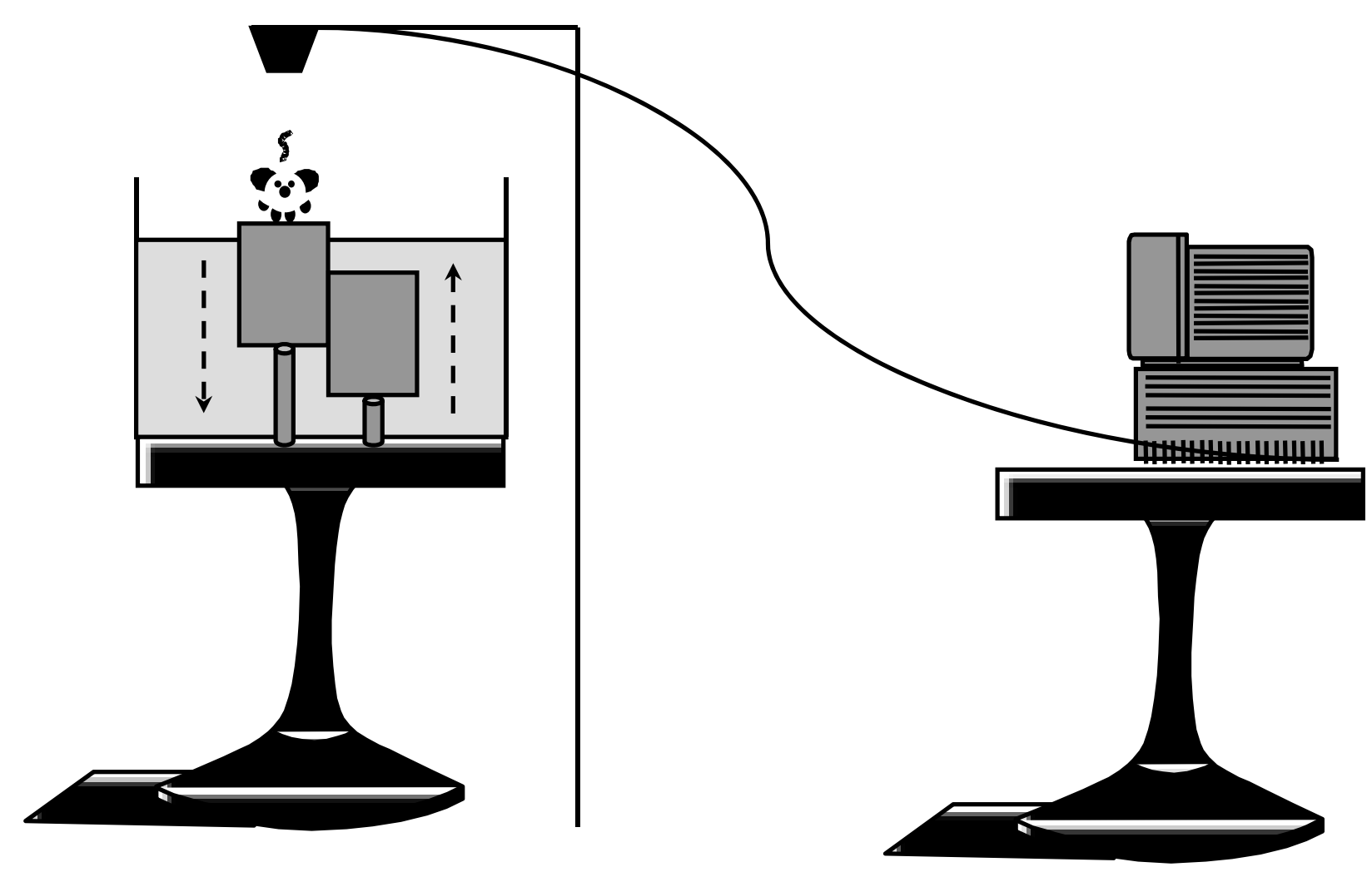




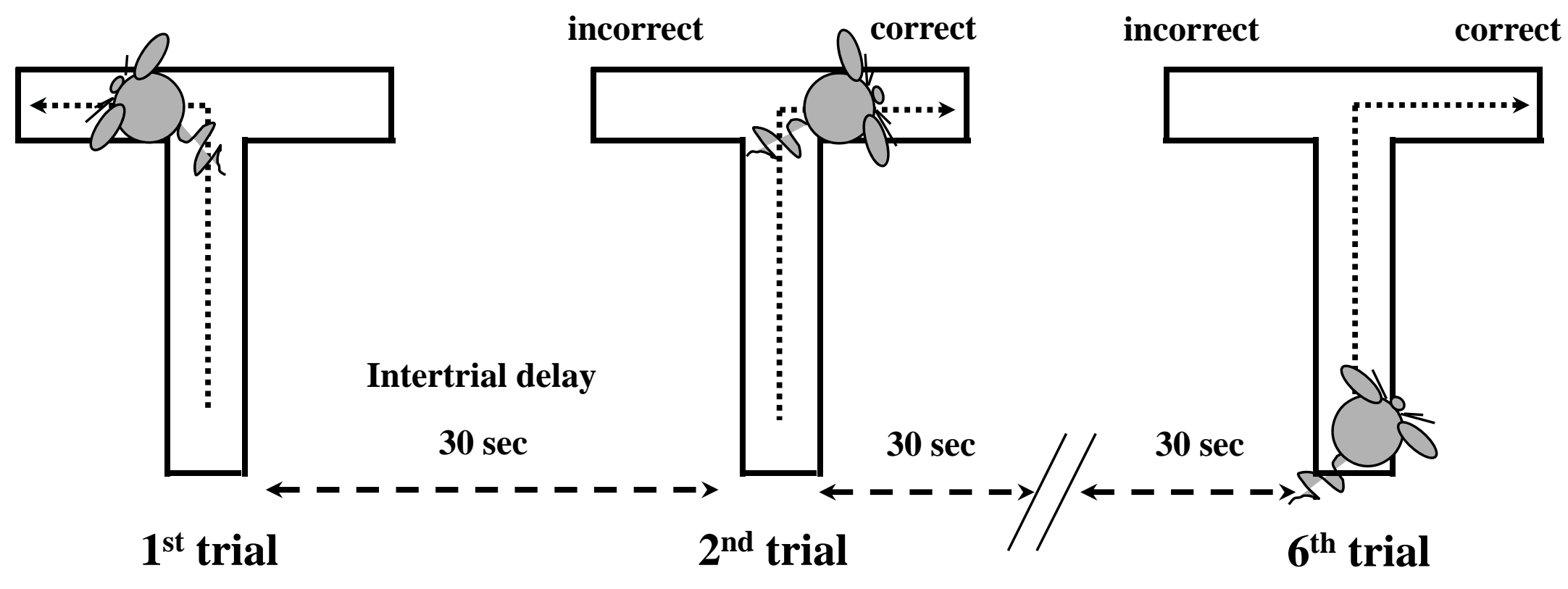




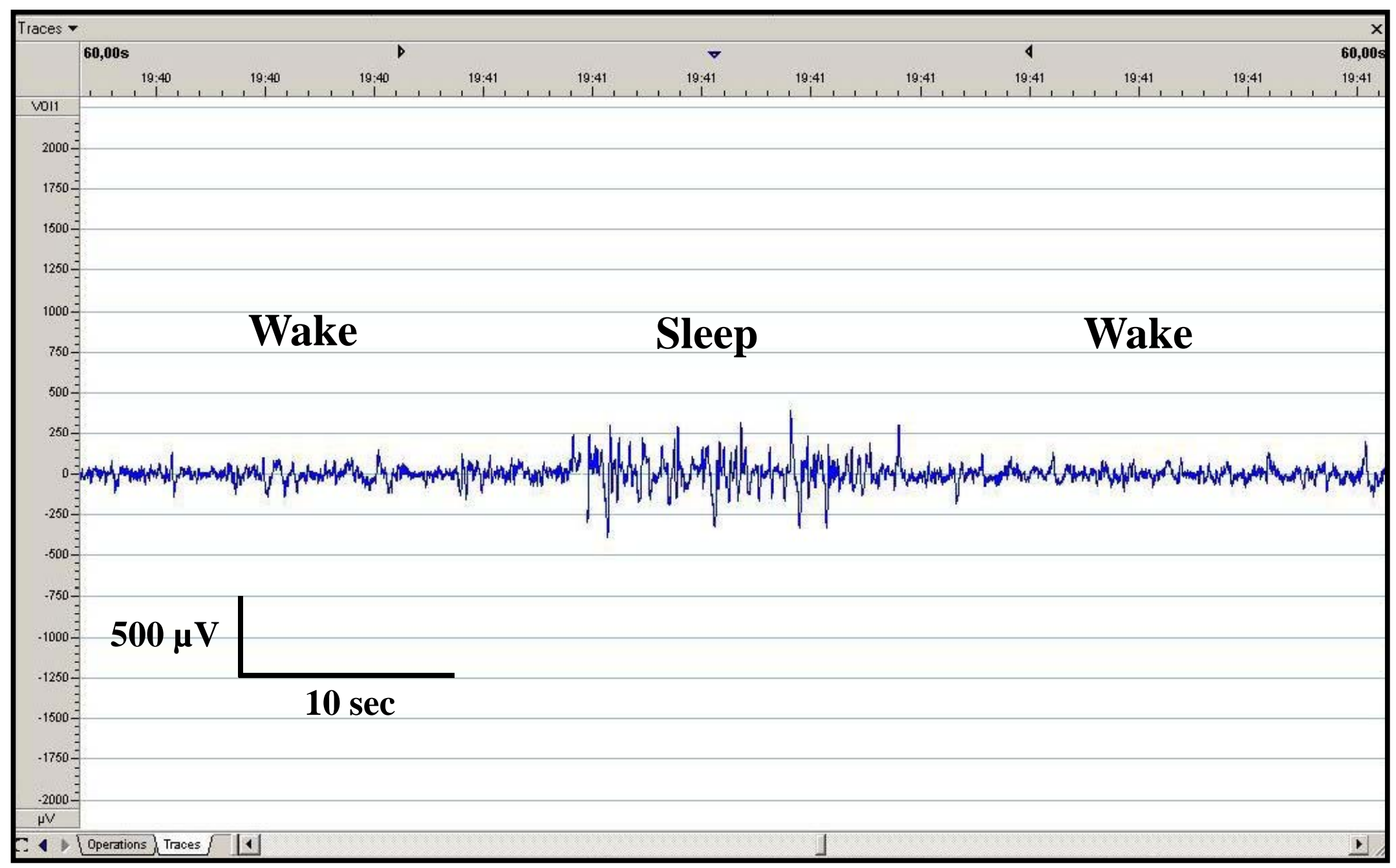




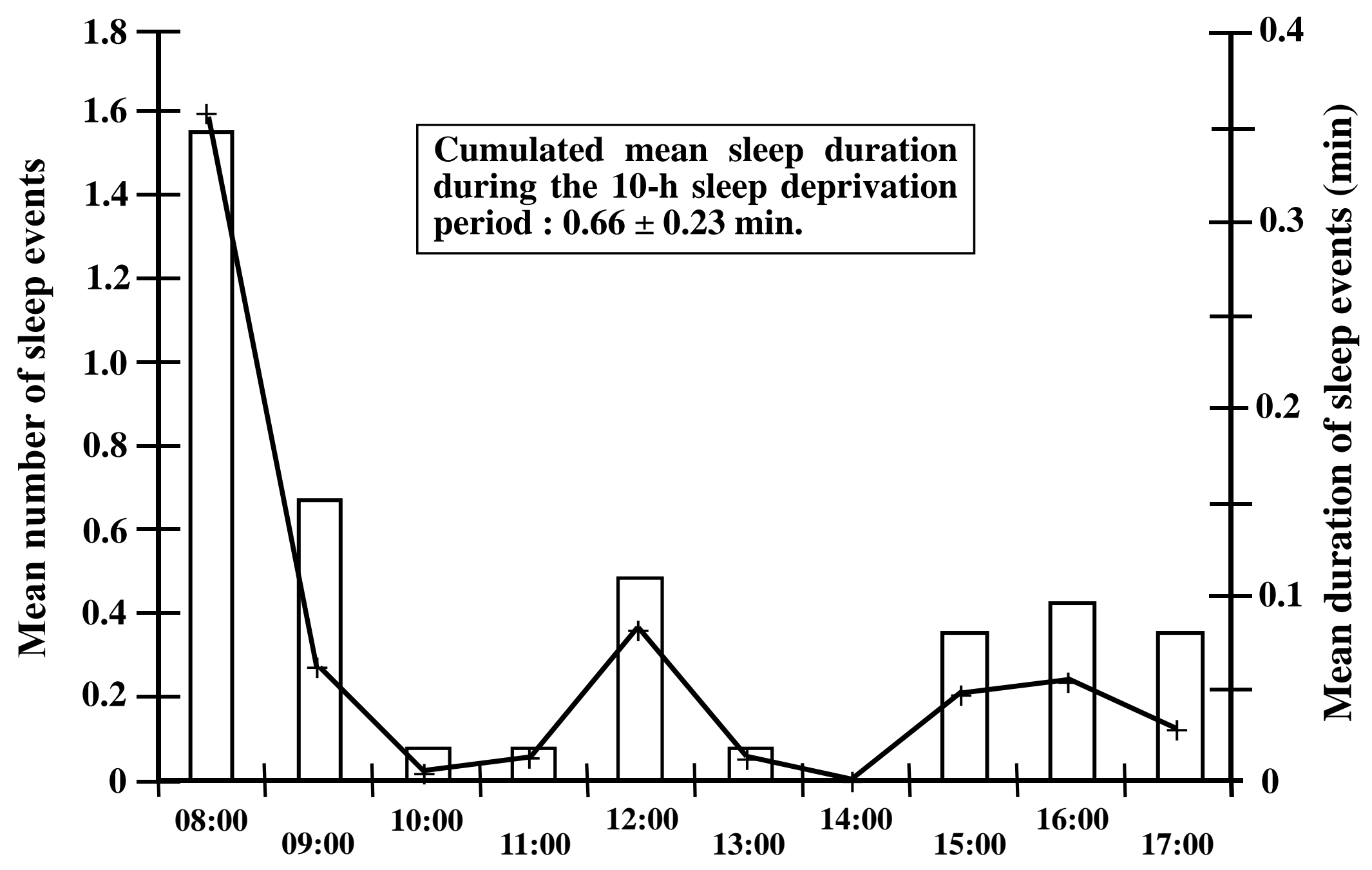




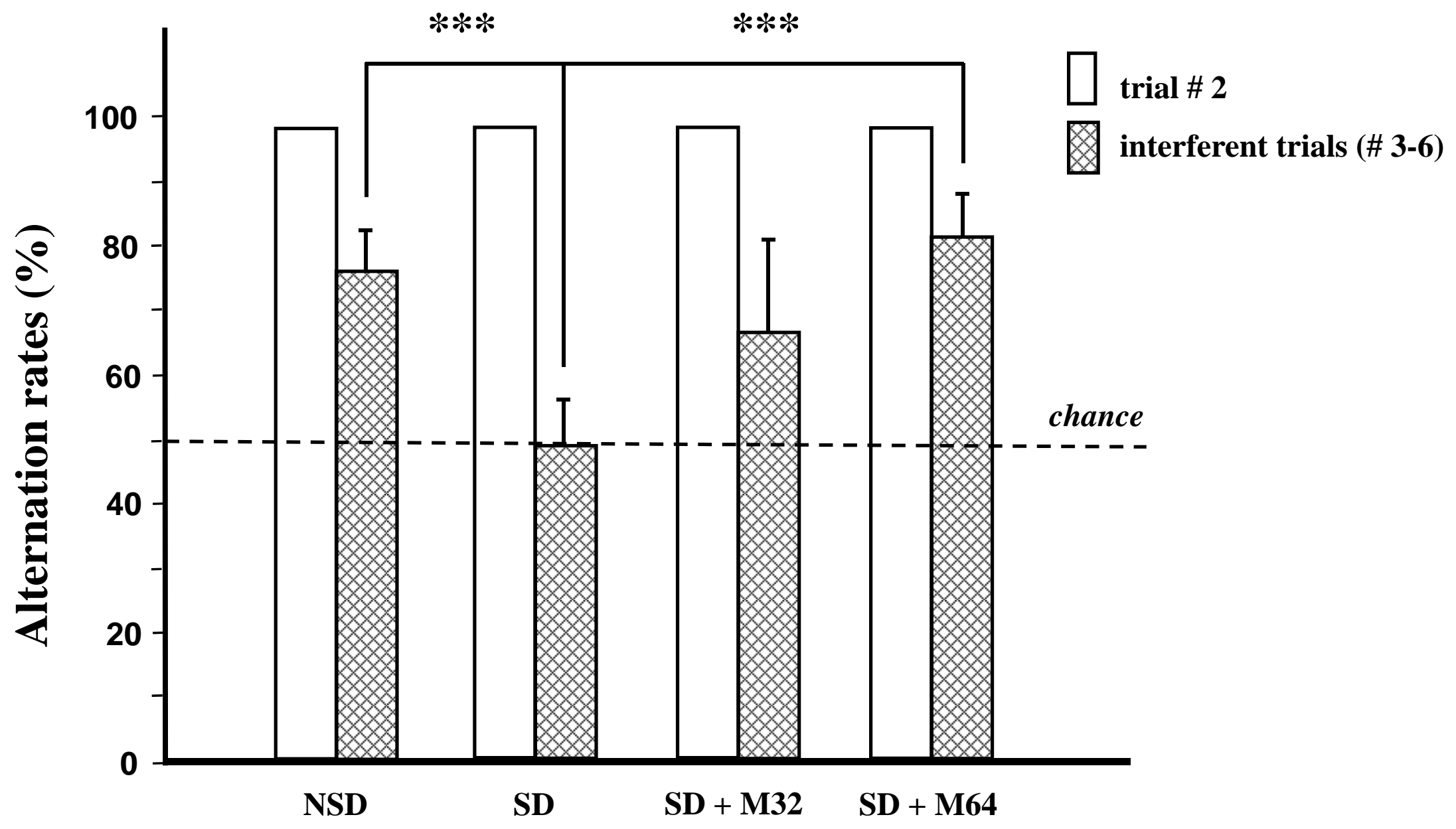




\begin{tabular}{|l|c|c|c|}
\hline & NSD & SD & SD + M64 \\
\hline $\begin{array}{l}\text { CA1 } \\
(F(2,9)=4.5 ; p<0.04)\end{array}$ & $125 \pm 12$ & $102 \pm 5^{*}$ & $115 \pm 9^{\text {n.s. }}$ \\
\hline $\begin{array}{l}\text { Dentate gyrus } \\
(F(2,9)=7.36 ; p<0.01)\end{array}$ & $65 \pm 5$ & $53 \pm 4^{*}$ & $58 \pm 8^{\text {n.s. }}$ \\
\hline $\begin{array}{l}\text { Frontal cortex } \\
(F(2,9)=3.98 ; p=0.05)\end{array}$ & $99 \pm 6$ & $84 \pm 4^{*}$ & $91 \pm 8^{\text {n.s. }}$ \\
\hline $\begin{array}{l}\text { Amygdala } \\
(F(2,9)=5.6 ; p<0.03)\end{array}$ & $60 \pm 5$ & $52 \pm 4^{*}$ & $62 \pm 7^{\text {n.s. }}$ \\
\hline $\begin{array}{l}\text { Anterior } \\
\text { hypothalamus } \\
(F(2,9)=6.08 ; p<0.02)\end{array}$ & $114 \pm 15$ & $88 \pm 10^{*}$ & $111 \pm 11^{\text {n.s. }}$ \\
\hline $\begin{array}{l}\text { Supraoptic nucleus } \\
(F(2,9)=10.7 ; p<0.004)\end{array}$ & $84 \pm 6$ & $69 \pm 7^{*}$ & $85 \pm 7^{\text {n.s. }}$ \\
\hline
\end{tabular}

